\title{
3D Numerical and Experimental Study on Paraffin Wax Melting in Thermal Storage for the Nozzle-and-Shell, Tube-and-Shell, and Reducer-and-Shell Models
}

\author{
Agus Dwi Korawan, ${ }^{1,2}$ Sudjito Soeparman, ${ }^{1}$ \\ Widya Wijayanti, ${ }^{1}$ and Denny Widhiyanuriyawan ${ }^{1}$ \\ ${ }^{1}$ Mechanical Engineering, Brawijaya University, Malang, Indonesia \\ ${ }^{2}$ Mechanical Engineering, Ronggolawe College of Technology, Cepu, Indonesia \\ Correspondence should be addressed to Agus Dwi Korawan; ad_korawan@yahoo.co.id
}

Received 29 December 2016; Accepted 15 March 2017; Published 4 April 2017

Academic Editor: Dimitrios E. Manolakos

Copyright (C) 2017 Agus Dwi Korawan et al. This is an open access article distributed under the Creative Commons Attribution License, which permits unrestricted use, distribution, and reproduction in any medium, provided the original work is properly cited.

Paraffin melting experienced in the nozzle-and-shell, tube-and-shell, and reducer-and-shell models in thermal storage with 3D numerical and experimental approach has been studied. The numerical study aims to evaluate the melting process and discover temperature distribution, liquid-solid interface, liquid fraction, and the average surface Nusselt number, while the aim of this experimental study is to determine the distribution of melting temperature. The comparison of temperature distribution between the numerical approach and experimental one indicates a good agreement. The comparison result between the three models shows that the melting process of the nozzle-and-shell model is the best, followed by tube-and-shell and reducer-and-shell models, successively. To finish the melting process, the time required is $6130 \mathrm{~s}$ for the nozzle-and-shell model, while tube-and-shell model requires $8210 \mathrm{~s}$ and reducer-and-shell model requires $12280 \mathrm{~s}$.

\section{Introduction}

Storing thermal energy in the latent heat is more profitable than in the sensible heat since the latent heat of certain materials is much greater than its sensible heat. Since it is stored in the latent heat, it involves the melting process. Materials used as thermal energy storage are commonly called Phase Change Materials (PCMs) which are materials that experience melting-solidification cycles. When the material changes from solid to liquid, it absorbs thermal energy from its surroundings. Conversely, when it changes from liquid to solid, it releases energy. Any energy absorbed or released when there is a phase change is known as latent heat [1].

Thermal storage is designed to collect energy during overproduction. Thus, one of the parameters that must be met is charge time [2] defined as the amount of time it takes for a thermal system to store energy. When storing the thermal energy, there will be heat transferred into the PCM triggering the melting process. Since the PCMs form is mainly solid, the heat transfer is a result of conduction. When it begins to melt and the liquid PCM starts to move, the transfer of heat is due to convection.

Several experimental or numerical researches have been conducted in order to discover the characteristics of melting heat transfer process of paraffin. Trp [3] conducted an experimental and numerical study on thermal storage system of shell-and-tube. The result showed that there is a good agreement between numerical approach and experimental one for paraffin nonisothermal melting. When charging, the temperature of the PCM increased over time until it started to melt. The heat transfer was dominated by conduction from the beginning of the heating process. Subsequently, there was a transition period where conduction and convection occurred simultaneously. Then, the melting process continued and the heat transfer is dominated by convection, which causes the solid particles of the PCM to sink to the bottom while the liquid particles rise resulting in the melting process to be faster at the top. 
Conduction in the beginning of melting process was also found by Hendra et al. [4] when analyzing the coefficient of convection which was initially very high and then decreased rather quickly to a specific value. Then, it slowly leveled out to a certain point before rising again. The decrease of the convection coefficient from a high value to a particular point in the beginning of heating process shows that the heat transfer was dominated by conduction. Furthermore, it was found that the liquid-solid interface moved from the top to the bottom in an axial direction mainly due to the role of the natural convection.

The form of liquid-solid interface indicates that there is heat transfer during the melting process, as proposed by Dhaidan et al. [5]. He conducted experimental and numerical research on the melting process within a square container. The container was subjected to constant heat flux on the side of the vertical wall while the other side was isolated. The result is that the melting was dominated by conduction at an early stage as marked by the liquid-solid interface which was parallel to the vertical hot wall. At a later time, the convection began to be promoted and the liquid-solid interface began to form an arch. The same thing was also stated by Ho and Gao [6]. The convection flow developed in the melt and acted as the mechanism of convection in that area, yielding a higher melting rate at the top of the enclosure as shown by the curvature of the liquid-solid interface which is higher.

Clearly, Nusselt number describes four stages of heat transfer during the melting process, which are conduction, transition, strong convection, and vanishing convection. As told by Shokouhmand and Kamkari [7], they conducted an experimental research on the characteristics of melting heat transfer of lauric acid in a one-side heated vertical rectangular thermal storage unit. The result is that the first stage is conduction which is the dominant mode of heat transfer in the early stage of the melting process and then followed by a short transition. Further, convection dominated the rest of the melting process. The intensity of convection began to decline when the liquid-solid interface reached the opposite wall.

The enthalpy-porosity method for numerical analysis of the melting process of paraffin in shell-and-tube heat exchanger was applied by Hosseini et al. [8]. In the charging process, it shows a good agreement between the numerical simulation result and the experimental one regarding the measurement of PCM temperature, even compared with other studies which are compatible. In addition to that, it was also proposed that heat transfer from heat exchanger to PCM was highly influenced by convection on the part of the liquid layer. The experimental study shows that a sharp rise in temperature takes place at the top of the shell due to the effect of PCM buoyancy.

A comparison between heating on vertical walls and heating on horizontal walls was done by Arasu and Mujumdar [9]. They conducted a numerical analysis on the melting process of paraffin wax with $\mathrm{Al}_{2} \mathrm{O}_{3}$ in a square enclosure. The temperature of the hot wall was kept constant at $330 \mathrm{~K}$ and the cold wall (in front of the hot wall) was also constant at $300 \mathrm{~K}$, with the other wall being adiabatic. The result showed that the melting rate and the energy stored for heating the vertical wall were greater than that for the heating on the horizontal wall. On the other hand, the use of corrugated heat exchanger wall was conducted by Kousksou et al. [10]. They conducted a numerical study on the melting in a rectangular cavity with a corrugated bottom wall where the other wall was isolated. The temperature of the bottom wall was maintained at $38.3^{\circ} \mathrm{C}$. The cavity was filled with solid gallium with an initial temperature of $28.3^{\circ} \mathrm{C}$. The result showed that there was an increase of melting rate in the value of the amplitude of the surface waves. The use of corrugated surfaces allowed the increase of heat transfer between the corrugated surface and the PCM.

As a PCM, paraffin offers many advantages over other materials as stated by Sharma et al. [11]. It is said that paraffin is reliable, cheaper, and noncorrosive, is chemically stable below $500^{\circ} \mathrm{C}$, and shows little change in volume when melted. According to Ukrainczyk et al. [12], paraffin melts at a temperature of 41 to $75^{\circ} \mathrm{C}$, overall enthalpy change is between 228 and $169 \mathrm{~J} / \mathrm{g}$, thermal conductivity is between 0.19 and $0.21 \mathrm{~W} / \mathrm{mK}$, and change in volume when melted reaches $14.8 \%$. According to Gasia et al. [13], paraffin is not harmful to health, phase change temperature range is of $50-61^{\circ} \mathrm{C}$, and enthalpy is of $120.11 \mathrm{~kJ} / \mathrm{kg}$. To find out the latent heat and melting temperature, Differential Thermal Analysis (DTA) or Differential Scanning Calorimeter (DSC) was used.

This $3 \mathrm{D}$ numerical study aims to evaluate the melting process of nozzle-and-shell, tube-and-shell, and reducer-andshell models. The main features are temperature distribution, contour of liquid-solid interface, liquid fraction, and surface Nusselt number, while the experimental study is used for validation.

\section{Materials and Methods}

The scheme of the research is shown in Figure 1(a). The test module is nozzle-and-shell model and the nozzle is made of copper with a thickness of $0.5 \mathrm{~mm}$ and the shell is made of PVC with a thickness of $3 \mathrm{~mm}$. The isolator is made of Styrofoam with a thickness of $10 \mathrm{~mm}$. The position of the test module is vertical. The dimensions and test module are shown in Figure 1(b).

A thermocouple was placed at the inlet of test module $\left(T_{\text {in }}\right)$ and at the outlet of test module $\left(T_{\text {out }}\right)$. Three thermocouples $\left(T_{1}, T_{2}\right.$, and $\left.T_{3}\right)$ were embedded into the paraffin at a depth of $3 \mathrm{~mm}$ and placed at different heights to measure temperature distribution during the melting process.

Three models used to compare the melting process of paraffin are shown in Figure 2, namely, nozzle-and-shell, tube-and-shell, and reducer-and-shell models.

The numerical analysis uses Ansys Fluent software to process the governing equations. The model is made in the subprogram of Geometry, which is the system component of Ansys, and the result is shown in Figure 2. Furthermore, the model is exported to the program component, Mesh, to be generated and bounded to the field required.

In the melting process, the hot wall is set at a constant temperature of $330 \mathrm{~K}$ and the other wall is adiabatic. The initial temperature of paraffin is $301 \mathrm{~K}$. User Defined Functions (UDFs) are used to calculate the density, thermal conductivity, and viscosity of paraffin based on its temperature. 


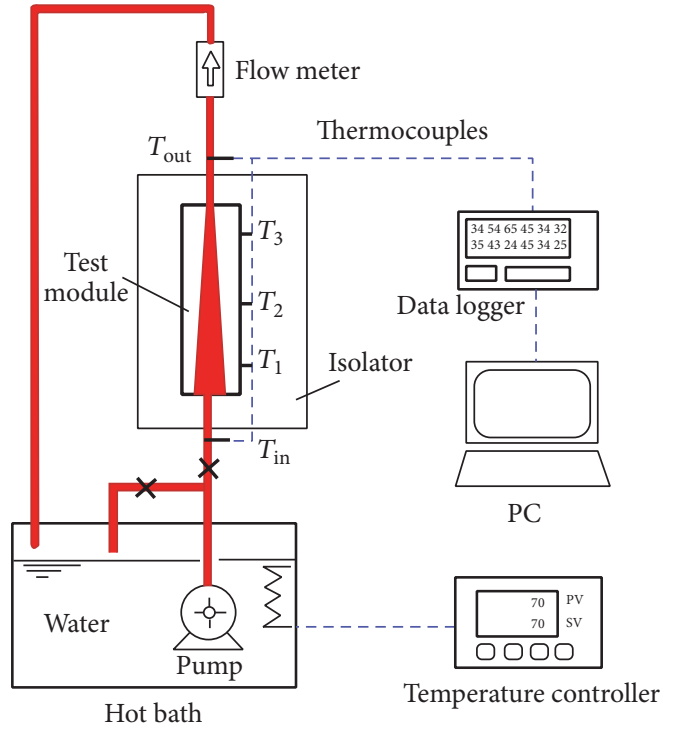

(a)
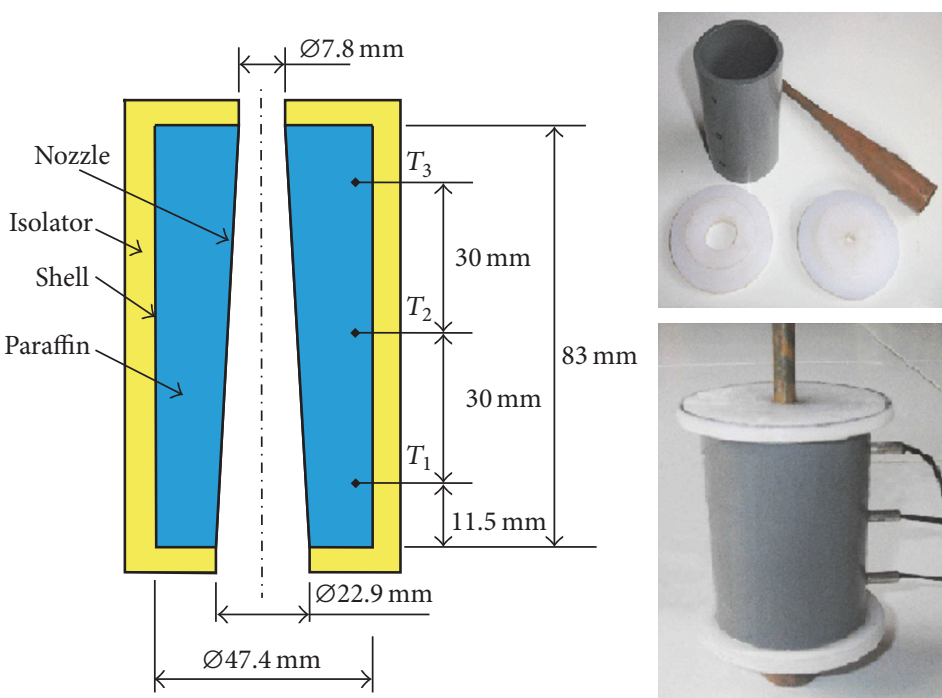

(b)

FIGURE 1: (a) Experimental set-up. (b) Detail of size and picture of nozzle-and-shell test module.
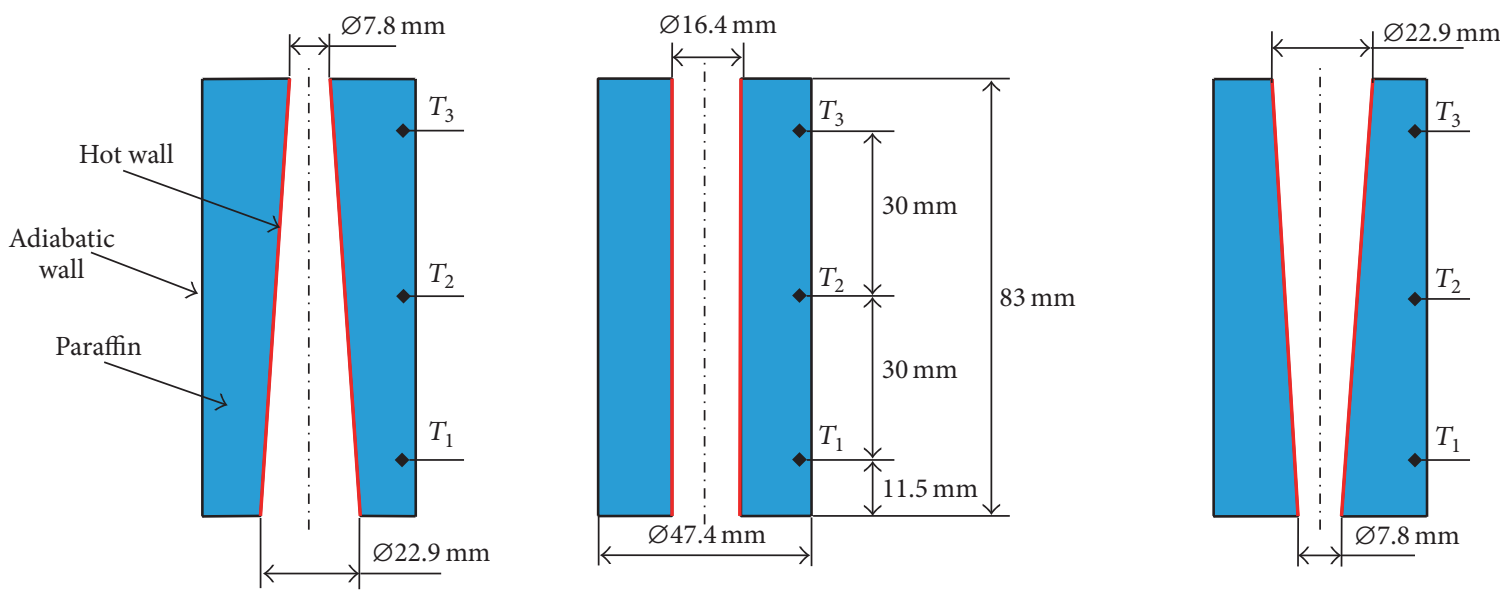

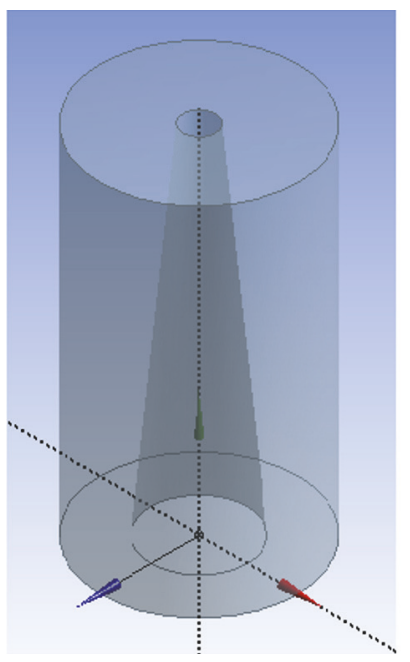

Nozzle-and-shell model

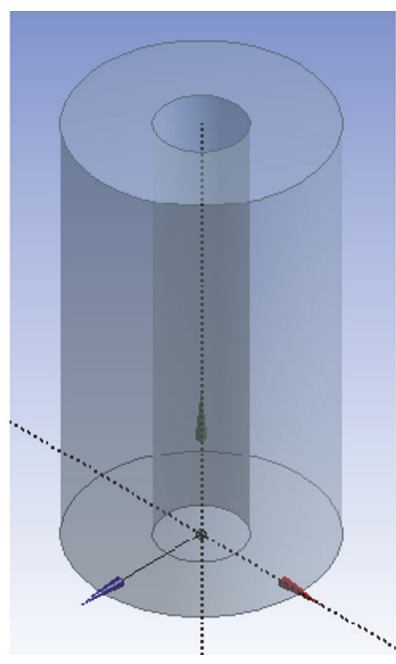

Tube-and-shell model

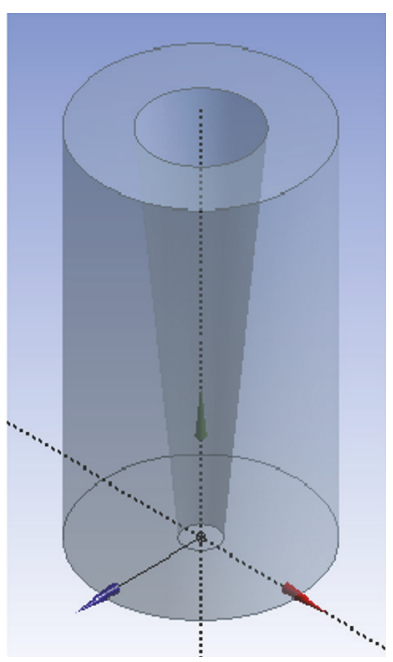

Reducer-and-shell model

FIgURE 2: Model for numerical analysis. 


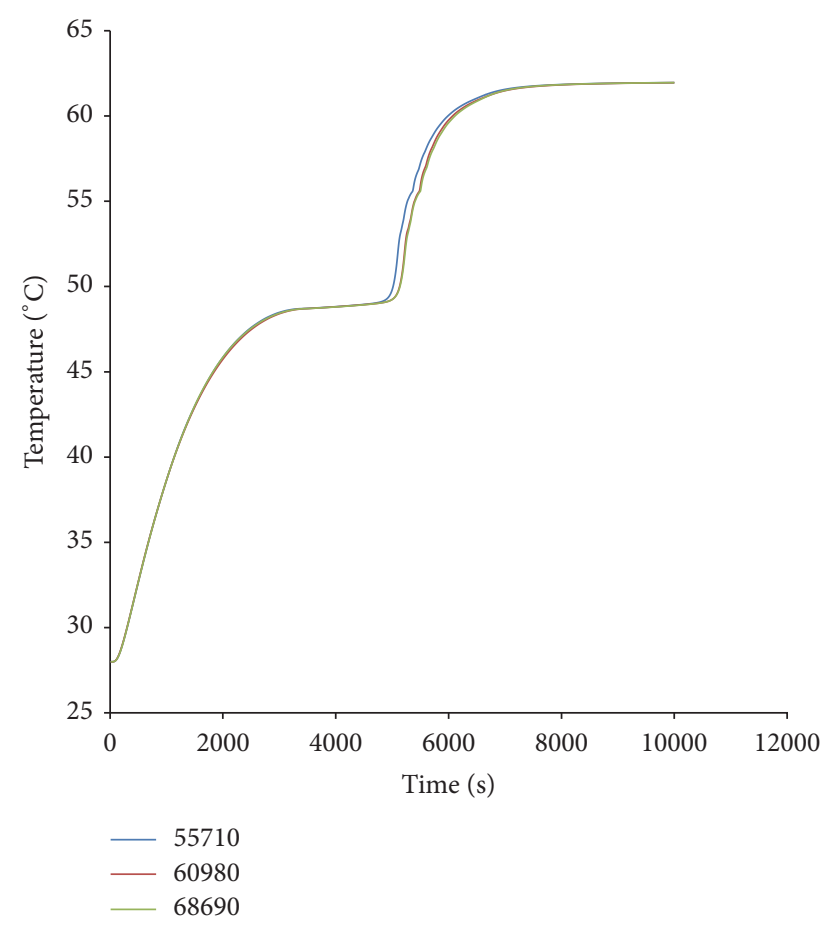

FIgURE 3: Temperature distribution of $T_{1}$ with grid size variation.

SIMPLE scheme was used as the method for a solution, while PRESTO scheme was adopted for the pressure correction equation. First-order upwind scheme was used for solving the momentum and energy equations. Under relaxation factors, pressure, density, momentum, and energy were $0.3,1,0.7$, and 1 , respectively. Convergence absolute criterion for continuity was set to $10^{-3}$ and, for energy, was set to $10^{-7}$. The time step for integrating the temporal derivatives was set to $1 \mathrm{~s}$.

Figure 3 presents different grid meshing for the cases which were tested at the primary calculation. Three grid sizes, including 55710, 60980, and 68690 cells, were examined to check the independency for the numerical solution. Therefore, 60980 cells were used in the numerical considering both accuracy and time.

The following are assumptions found in this numerical study: (1) thermophysical properties of paraffin depended on temperature; (2) liquid flow of the paraffin in the melting process was laminar; (3) liquid paraffin was Newtonian; (4) the viscous dissipation was neglected; (5) the variation of volume as a result of the melting was neglected.

The enthalpy-porosity technique $[8,9]$ was used for modelling the melting process where liquid-solid interface was not tracked explicitly. On the contrary, liquid fraction was calculated at each iteration based on the balance of enthalpy.

The enthalpy is calculated as the sum of sensible enthalpy, $h$, and latent heat, $H[9,14]$ :

$$
H=h+\Delta H,
$$

where

$$
h=h_{\mathrm{ref}}+\int_{T_{\mathrm{ref}}}^{T} c_{p} d T
$$

and $h_{\text {ref }}$ is reference enthalpy, $T_{\text {ref }}$ is reference temperature, and $c_{p}$ is specific heat at constant pressure.

Liquid fraction, $\beta$, is defined as

$$
\begin{aligned}
& \beta=0 \quad \text { if } T<T_{\text {solidus }} \\
& \beta=1 \quad \text { if } T>T_{\text {liquidus }} \\
& \beta=\frac{T-T_{\text {solidus }}}{T_{\text {liquidus }}-T_{\text {solidus }}} \text { if } T_{\text {solidus }}<T<T_{\text {liquidus }} .
\end{aligned}
$$

The latent heat content of the material can now be written as follows:

$$
\Delta H=\beta L
$$

where $L$ is latent heat of the material.

The content of latent heat of the material can vary between zero (solid) and $L$ (liquid).

For the melting problems, the energy equation is written as

$$
\frac{\partial}{\partial t}(\rho H)+\Delta \cdot(\rho v H)=\Delta \cdot(k \Delta T)+S,
$$

where $H$ stands for the enthalpy of the PCM, $\rho$ is for density, $v$ is for velocity, $T$ is for temperature, $k$ is the thermal conductivity, and $S$ stands for volumetric heat source term and it is equal to zero in the present study [10].

To find out the thermal characteristics of paraffin, the test of Differential Thermal Analysis (DTA) was conducted by using Alumina $\left(\mathrm{Al}_{2} \mathrm{O}_{3}\right)$ for its reference of material and setting $1^{\circ} \mathrm{C} / \mathrm{min}$ for its heating rate. A summary was successfully obtained as provided in Table 1.

The density and viscosity of paraffin depend on its temperature. By plotting its values as temperature function, data obtained is shown in Figures 4 and 5.

\section{Result and Discussion}

Validation was performed by comparing the result of numerical analysis of the model to the result of the experimental. The comparison of temperature distribution of $T_{1}, T_{2}$, and $T_{3}$ on the nozzle-and-shell model is shown in Figure 6. From the graph, it can be seen that the numerical result and experimental result have the same pattern, even though the values are different. It is because the experimental study used an insulator to reduce the heat transfer from the shell wall towards the environment, while, in the numerical study, the shell is adiabatic.

Before the experiment started, water was boiled in a water bath until it reached a temperature of $330 \mathrm{~K}$. During the heating process, conduction occurred through the pipe causing the temperature of paraffin to rise so that the values of $T_{3}, T_{2}$, and $T_{1}$ were initially higher than the numerical. During the melting process, heat transfer from paraffin towards the environment still occurred which caused the values of $T_{3}, T_{2}$, and $T_{1}$ to become lower than that of the numerical. The density difference, at the end of the melting process, caused liquid paraffin with higher temperature to be 
TABLE 1: The properties of paraffin.

\begin{tabular}{lc}
\hline Property & Value \\
\hline${ }^{\mathrm{a}}$ Density $\left(\mathrm{kg} / \mathrm{m}^{3}\right)$ & $\frac{750}{0.001(T-319.15)+1}$ \\
${ }^{\mathrm{b}}$ Specific heat $(\mathrm{J} / \mathrm{kgK})$ & 3100 \\
${ }^{\mathrm{a}}$ Thermal conductivity of solid $(\mathrm{W} / \mathrm{mK})$ & 0.21 \\
${ }^{\mathrm{a}}$ Thermal conductivity of liquid $(\mathrm{W} / \mathrm{mK})$ & 0.12 \\
${ }^{\mathrm{a}}$ Viscosity $\left(\mathrm{Ns} / \mathrm{m}^{2}\right)$ & $0.001 \exp \left(-4.25+\frac{1790}{T}\right)$ \\
${ }^{\mathrm{b}}$ Latent heat $(\mathrm{J} / \mathrm{kg})$ & 166000 \\
${ }^{\mathrm{b}}$ Solidus temperature $(\mathrm{K})$ & 321.7 \\
${ }^{\mathrm{b}}$ Liquidus temperature $(\mathrm{K})$ & 328.6 \\
\hline
\end{tabular}

${ }^{\mathrm{a}}$ Ref. [9].

${ }^{\mathrm{b}}$ Measured.

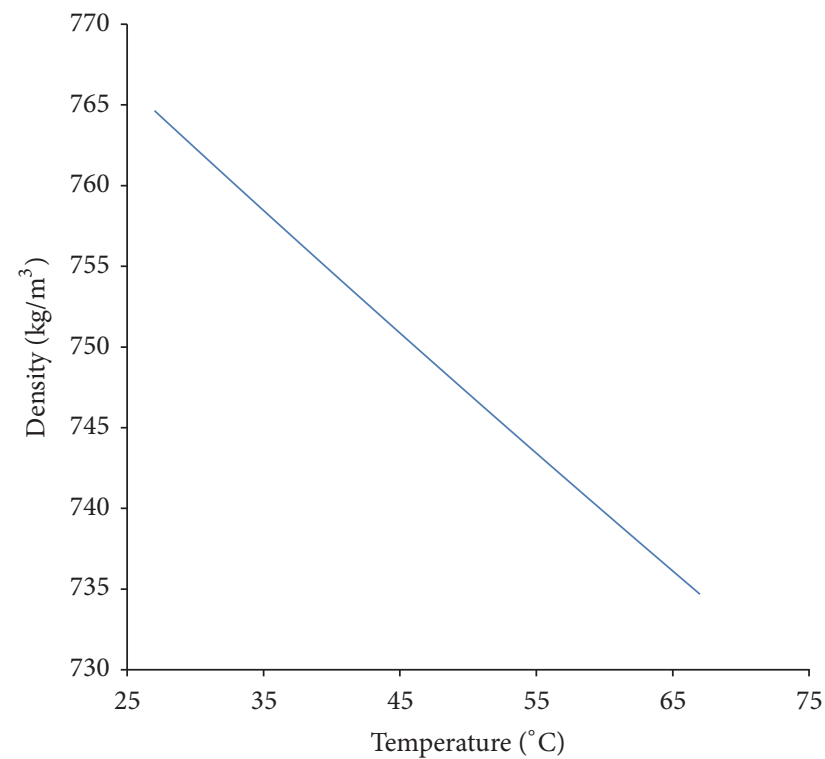

FIGURE 4: Density of paraffin.

on the top of the shell. Thus, the temperature of $T_{3}$ was the highest, followed by $T_{2}$ and $T_{1}$, respectively. Overall, a good agreement was overall between the numerical approach and experimental one. Thus, the next discussion uses the data of numerical analysis.

As a result of numerical study, temperature distribution of paraffin during the melting process of the nozzle-and-shell model is shown in Figure 7(a). The initial temperatures of $T_{1}, T_{2}$, and $T_{3}$ were the same. Next, there was an increase in temperature at different times where the temperature of $T_{1}$ rose first and was followed by $T_{2}$ and $T_{3}$, respectively. In this period, the heat transfer was conduction and the temperature of a point closer to the nozzle surface increased more rapidly.

The heat was absorbed by paraffin which increased the initial temperature to melting temperature. The heat was stored in the form of sensible heat, in that the temperature at measurement points rose over time. Then, the paraffin started changing from a solid to a liquid since the heat absorbed was used to change phase and the temperature in this time

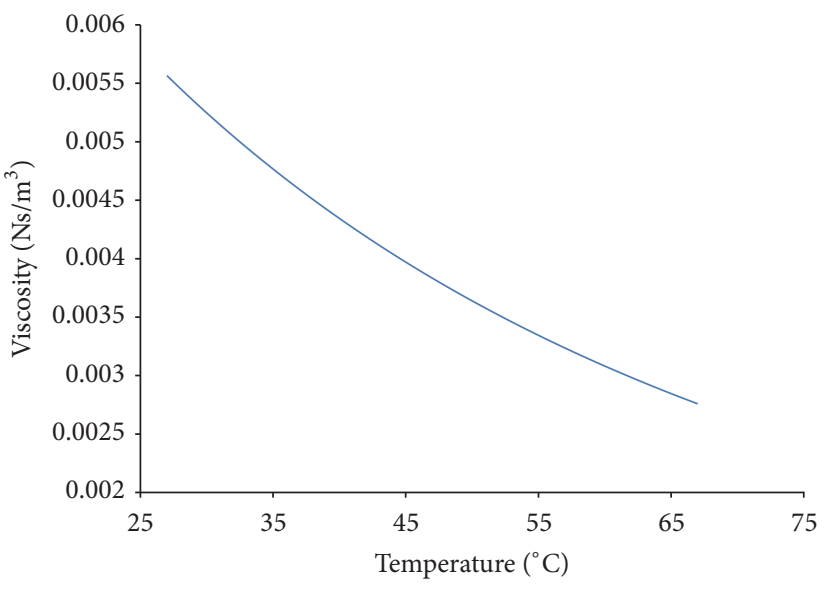

Figure 5: Viscosity of paraffin.

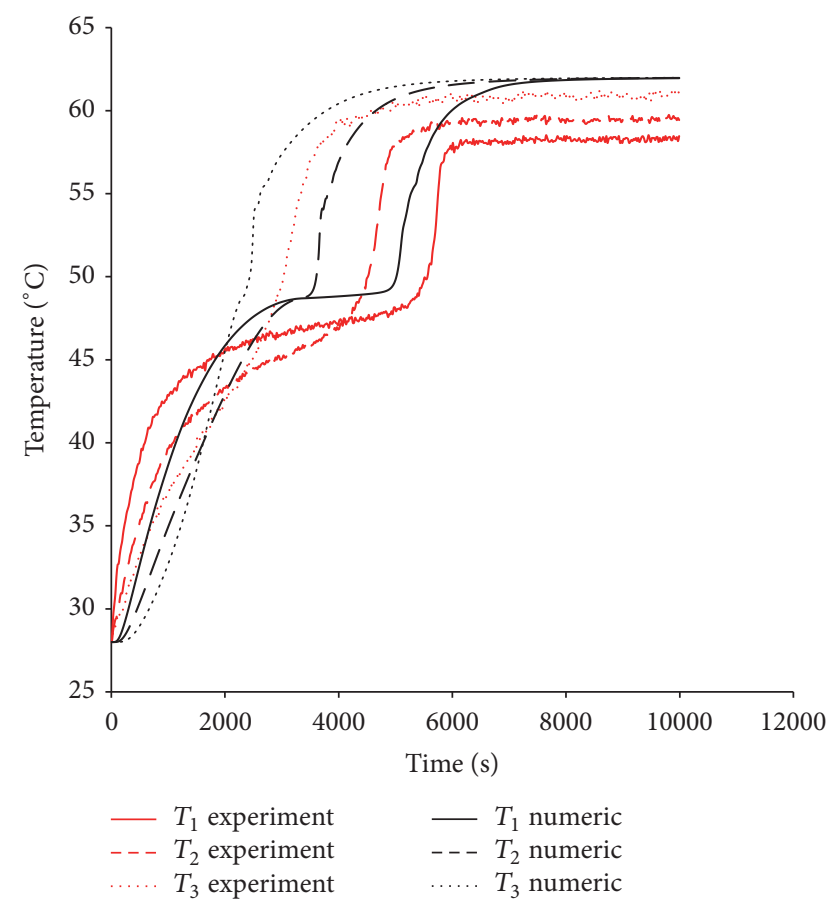

FIGURE 6: The comparison of temperature distribution of paraffin. 


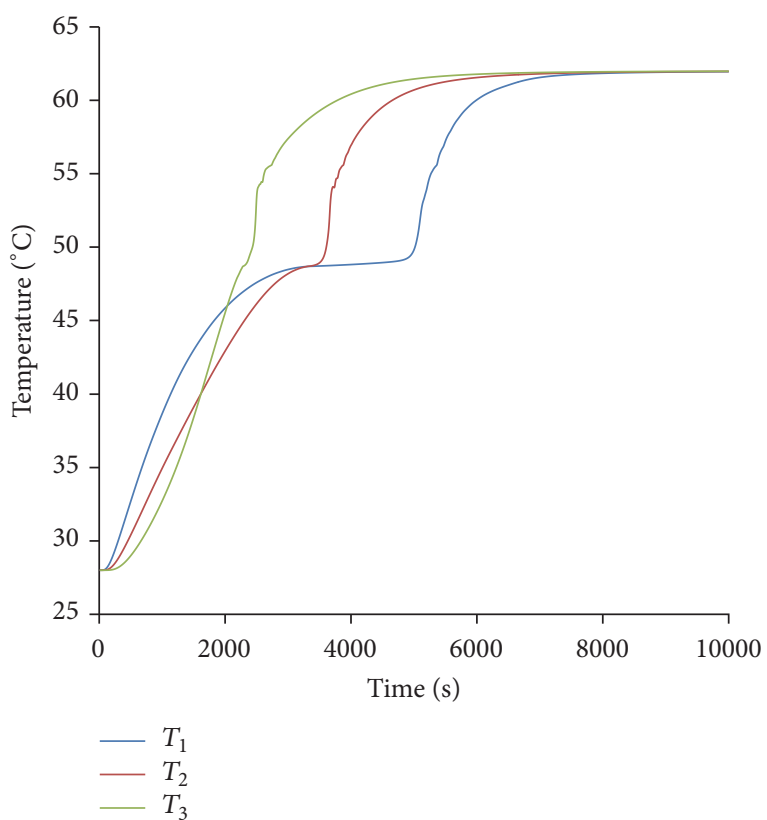

(a)

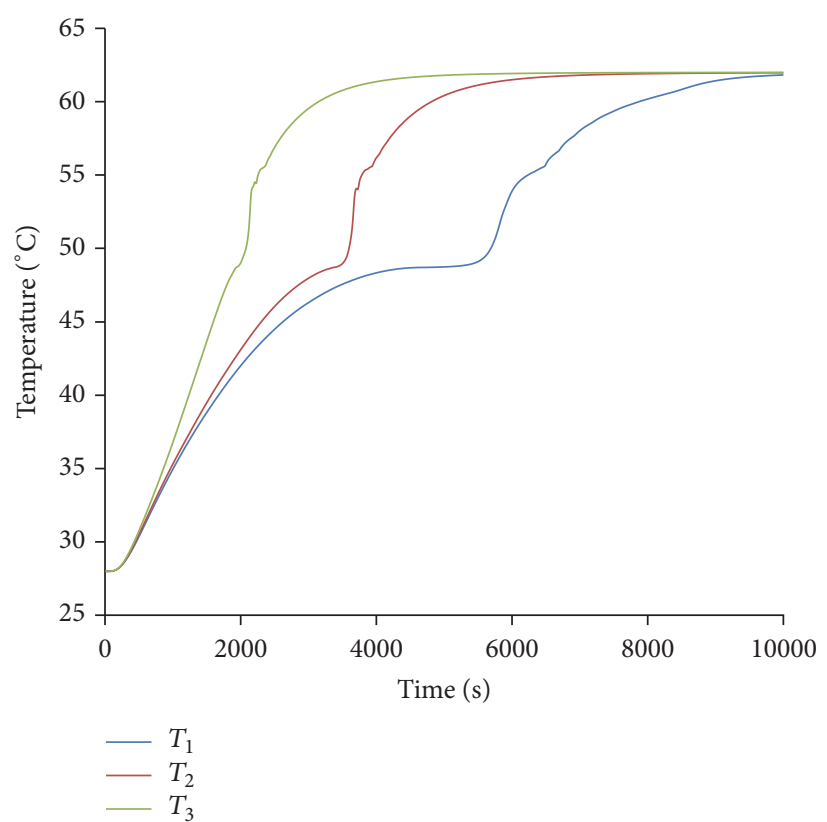

(b)

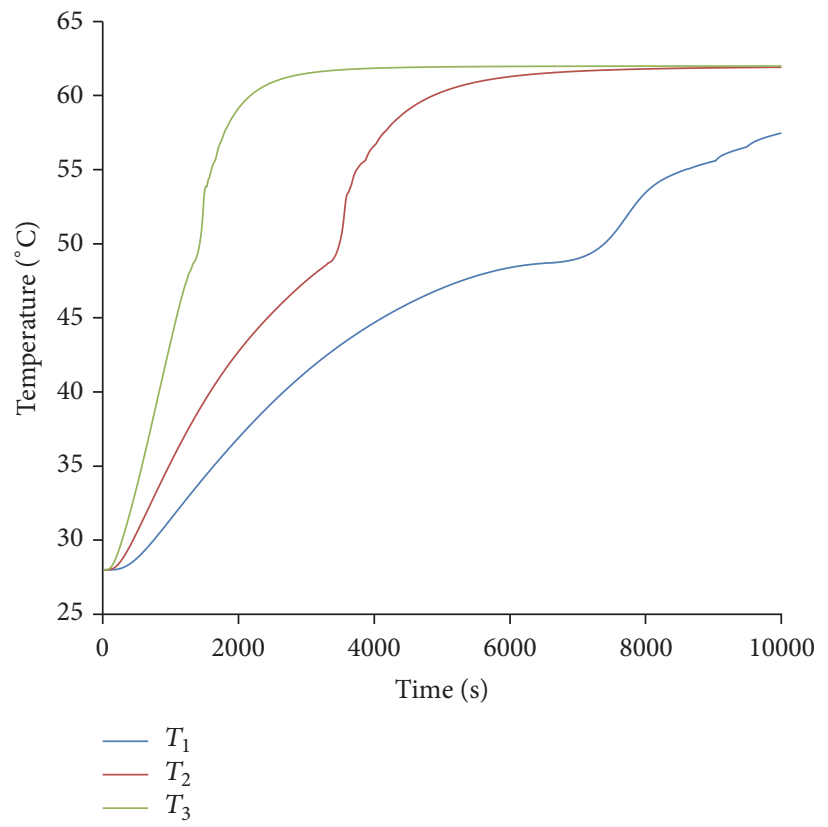

(c)

Figure 7: The temperature distribution of the paraffin: (a) nozzle-and-shell, (b) tube-and-shell, and (c) reducer-and-shell models.

tended to be constant over time and the heat was stored in the form of latent heat. After that, there was a change of paraffin temperature in which the heat absorbed was used to increase the temperature of paraffin until the temperature was the same with the temperature of the hot wall.

The temperature distribution in the tube-and-shell model experienced a difference compared to the nozzle-and-shell model (Figure 7(b)). The increase of temperatures in the early heating process was simultaneous as represented by the graphs of $T_{1}, T_{2}$, and $T_{3}$ that all coincide. It was because all temperature measurement points on the tube wall were the same distance apart, so at the beginning of conduction there was temperature uniformity at all points. Then, $T_{3}$ increased first since the melting process of the paraffin was at the top. After $T_{3}$ reached its melting temperature, it was followed by $T_{2}$ and $T_{1}$, respectively. After melting, the temperature of paraffin increased again until it was equal to the temperature of the hot wall.

The temperature distribution of reducer-and-shell model (Figure 7(c)) also underwent a difference compared with the 

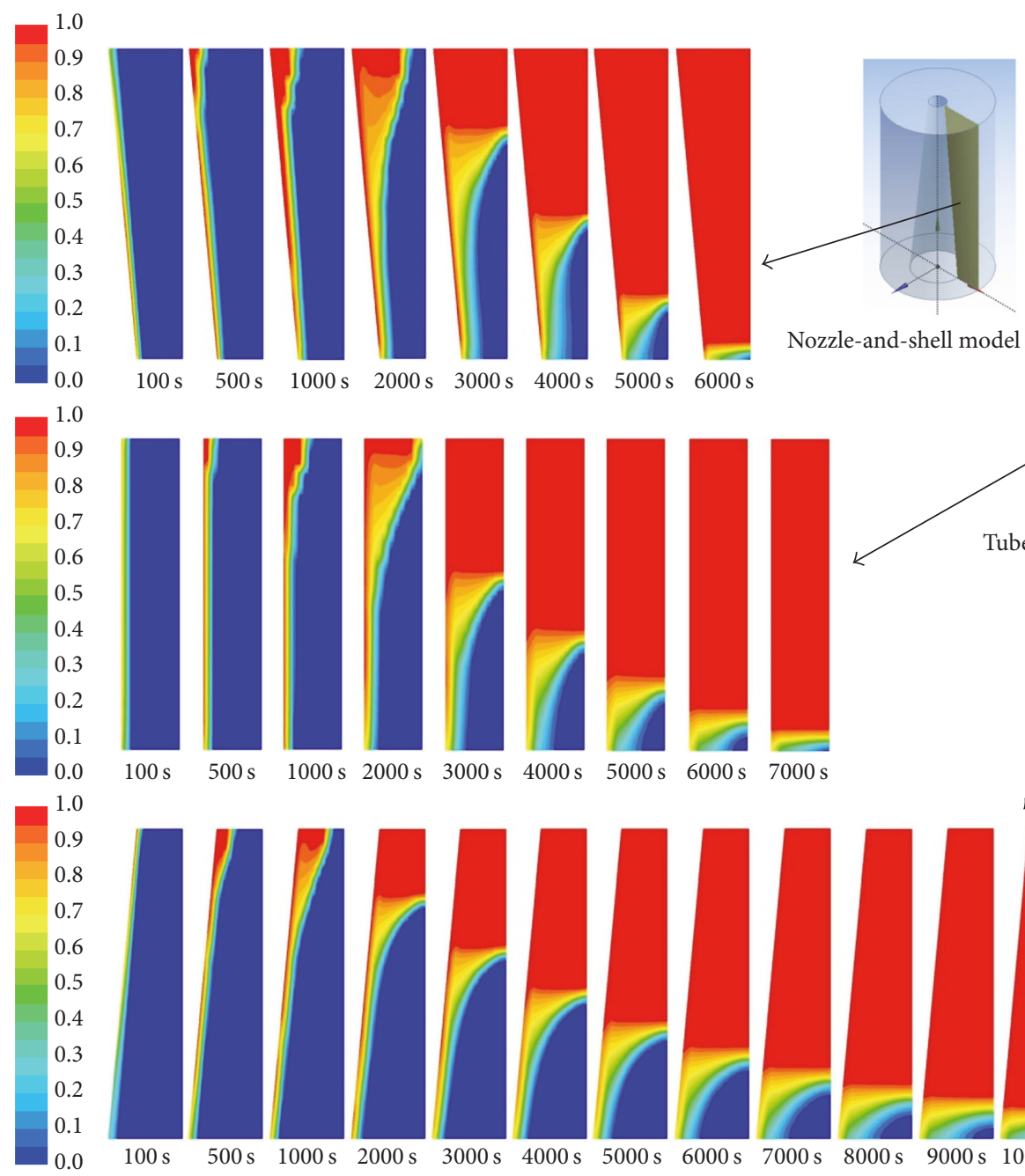

$100 \mathrm{~s}$

$500 \mathrm{~s} \quad 1000 \mathrm{~s}$

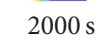

$3000 \mathrm{~s}$

Nozzle-and-shell model
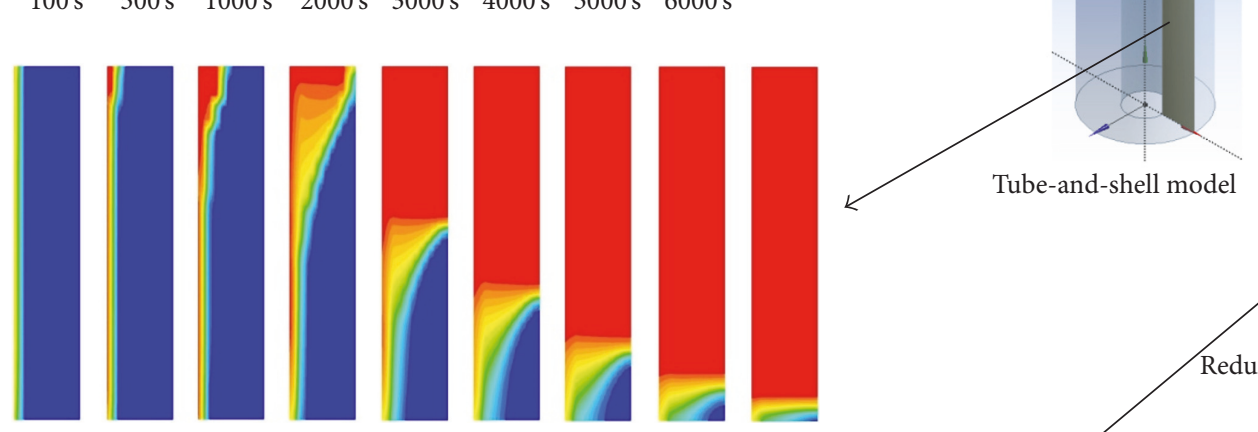

$500 \mathrm{~s}$

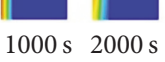

$3000 \mathrm{~s} 4000 \mathrm{~s}$

$5000 \mathrm{~s}$

$6000 s \quad 7000 s$
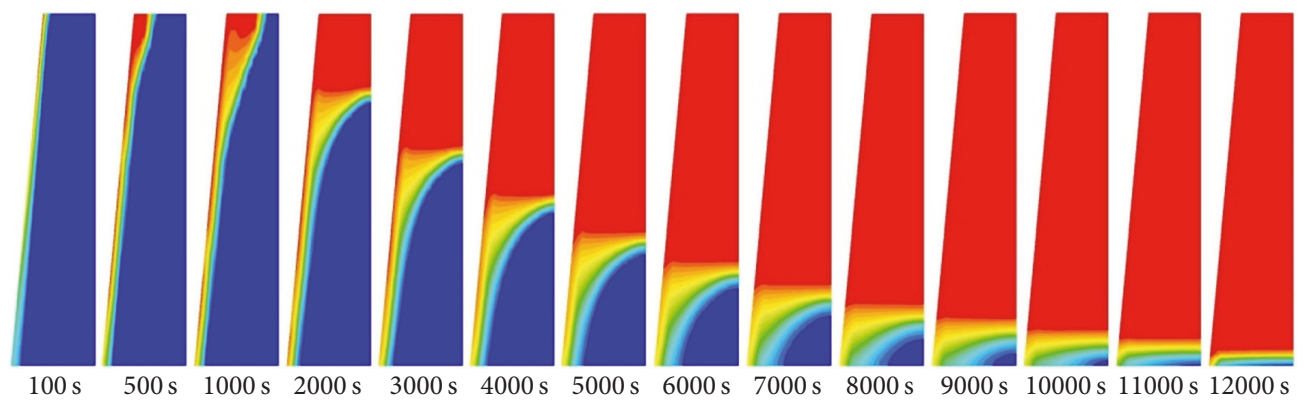

FIgURE 8: Contours of liquid-solid interface.

nozzle-and-shell and tube-and-shell models. An increase of temperatures at the beginning of heating process did not happen simultaneously. The temperature of $T_{3}$ increased first followed by $T_{2}$, and $T_{1}$, respectively. It was due to the distances of the measurement points towards the surface of the reducer varied, where the distance of $T_{3}$ towards the surface of the reducer was the closest, followed by $T_{2}$ and $T_{1}$. A sharp increase of temperature at the top of the shell was due to the effect of buoyancy forces of liquid paraffin and caused $T_{3}$ to increase until the temperature was the same with the temperature of the hot wall and followed by $T_{2}$ and $T_{1}$, respectively.

Figure 8 shows the comparison of the liquid-solid interface on the nozzle-and-shell, tube-and-shell, and reducerand-shell models. The figure was obtained by taking the visualization result of liquid fraction contours in vertical slice at different times. At the beginning of melting process, it was dominated by conduction, which was indicated by the liquid-solid interface which was parallel to the hot wall. The liquid paraffin rose parallel to the hot wall because there was a difference in density and gathered at the top resulting in the temperature of the top becoming greater. The melting process first occurred at the top and then the liquid paraffin moved down past the solid surface while releasing the heat. The movement of liquid paraffin was up and down forming the internal convection flow in which at this time the heat transfer was dominated by convection. Overall, the melting process of nozzle-and-shell model was the quickest, followed by tube-and-shell and reducer-and-shell models, respectively.

An important parameter of thermal storage is charging time, which is defined as the time it takes for a thermal system to store energy. It can be represented by the graph of liquid fraction, as shown in Figure 9. Liquid fraction is the comparison between the amount of liquid and the overall amount of paraffin; if the value is equal to 1 , it means all paraffin has already turned into liquid. The liquid fraction of nozzle-and-shell model reaches a value equal to 1 before it does in the tube-and-shell model. According to the data taken from the numerical result, the time required to reach the value of liquid fraction equal to 1 with the nozzle-and-shell model was $6130 \mathrm{~s}$, while the tube-and-shell model was $8219 \mathrm{~s}$, and the reducer-and-shell model was $12280 \mathrm{~s}$. Compared to 


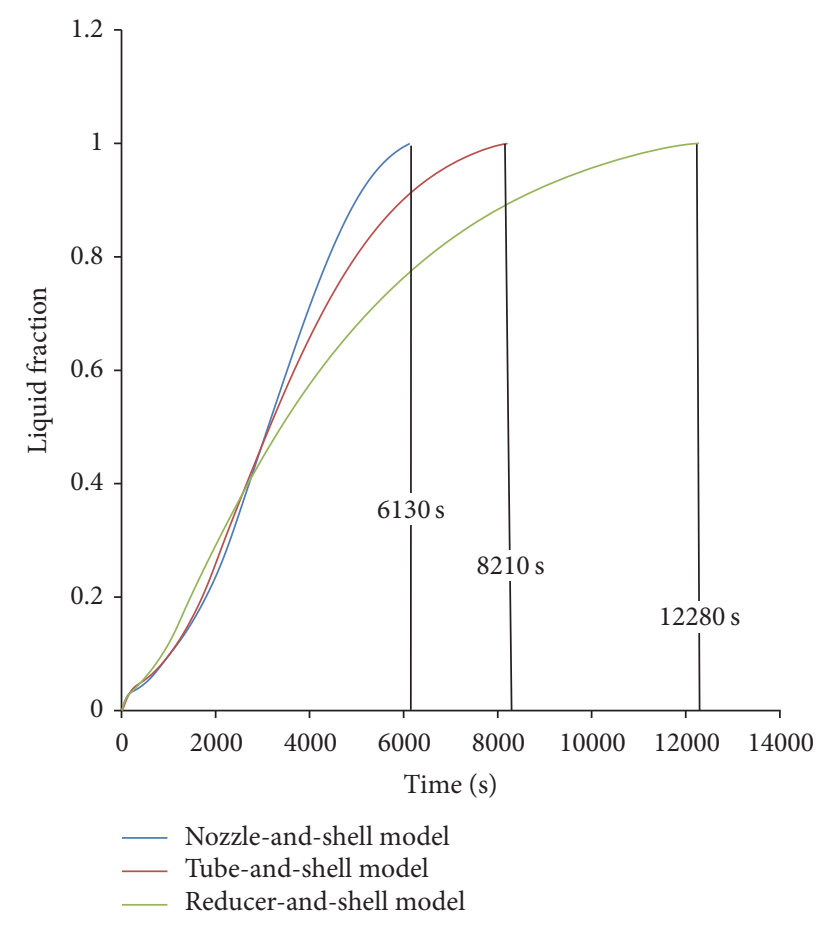

Figure 9: The comparison of liquid fraction.

the tube-and-shell model, the nozzle-and-shell model was $15.3 \%$ faster, and the reducer-and-shell model was $49.5 \%$ slower.

Although, overall, liquid fraction of the nozzle-and-shell model was faster than that of the tube-and-shell model, it was not the case at the start of the process where liquid fraction of the nozzle-and-shell model was not faster because of the effect of the convection at the early melting stage that was not dominant; after that, the effect of the convection became increasingly stronger with the increase of liquid fraction due to the hot wall in form of a nozzle. In contrast, reducerand-shell model where the hot wall was in form of reducer apparently cannot increase the convection compared to the one in form of tube.

Figure 10 shows the Nusselt numbers of three models; Nusselt number started with a relatively large value. After that, Nusselt numbers decreased rapidly at this stage of conduction. The melting process started to occur but there was no fluid movement. After that, there was a transition from conduction to convection and the liquid started to move because of the difference in density. It was followed by strong convection and ended by vanishing convection where all paraffin turned into liquid.

There were some differences in the length of time for the strong convection among the three models. For the nozzleand-shell model, it began from $400 \mathrm{~s}$ and was ended by $2400 \mathrm{~s}$, and it was $2000 \mathrm{~s}$. For the tube-and-shell model, it was $1450 \mathrm{~s}$. For the reducer-and-shell model, it was $1750 \mathrm{~s}$. The opposite was at vanishing convection in which the longest was on the reducer-and-shell model, faster one was with tube-and-shell model, and the fastest was with nozzle-and-shell model.

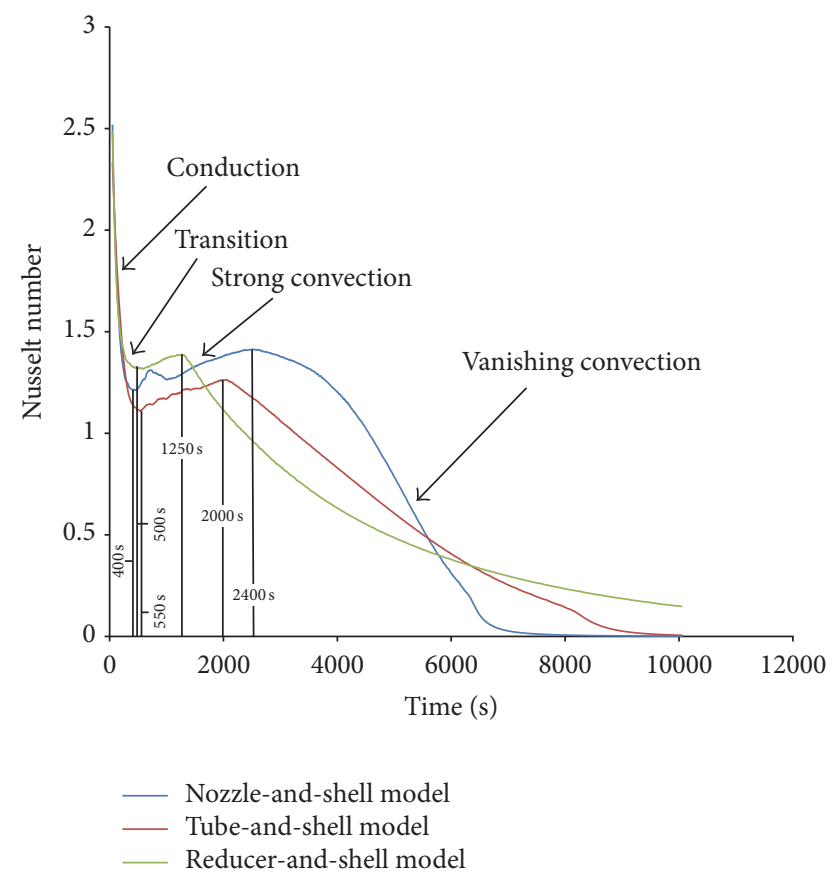

FIgURE 10: The average of surface Nusselt number.

To explain the occurrence of strong convection further, the data of Nusselt number and the liquid-solid interface were correlated as shown in Figure 11. The change of strong convection to vanishing convection occurred at the time where the liquid-solid interface lasted the longest. The line started from the bottom left corner and ended at the top right corner. The liquid-solid interface in the strong convection region increased lengthwise. Meanwhile, in the vanishing convection region, the liquid-solid interface became increasingly shorter.

\section{Conclusion}

There was a different pattern of paraffin temperature distribution on the nozzle-and-shell, tube-and-shell, and reducerand-shell models. The difference occurred at the beginning of the melting process caused by the distance from the measurement points to the hot wall. The close distance of the measurement points to the hot wall caused the temperature increase to be faster.

The melting process was initiated by the paraffin close to the hot wall. After that, the liquid paraffin rose parallel to the hot wall because there was a difference in density. It gathered at the top of the shell causing the temperature at the top to become greater. Thus, the melting process occurred first at the top of the shell.

The melting process finished when all paraffin had already turned into liquid. The nozzle-and-shell model finished first and followed by tube-and-shell and reducer-and-shell models, respectively. Compared to the tube-and-shell model, the nozzle-and-shell was $25.3 \%$ faster and the reducer-andshell was $49.5 \%$ slower. 


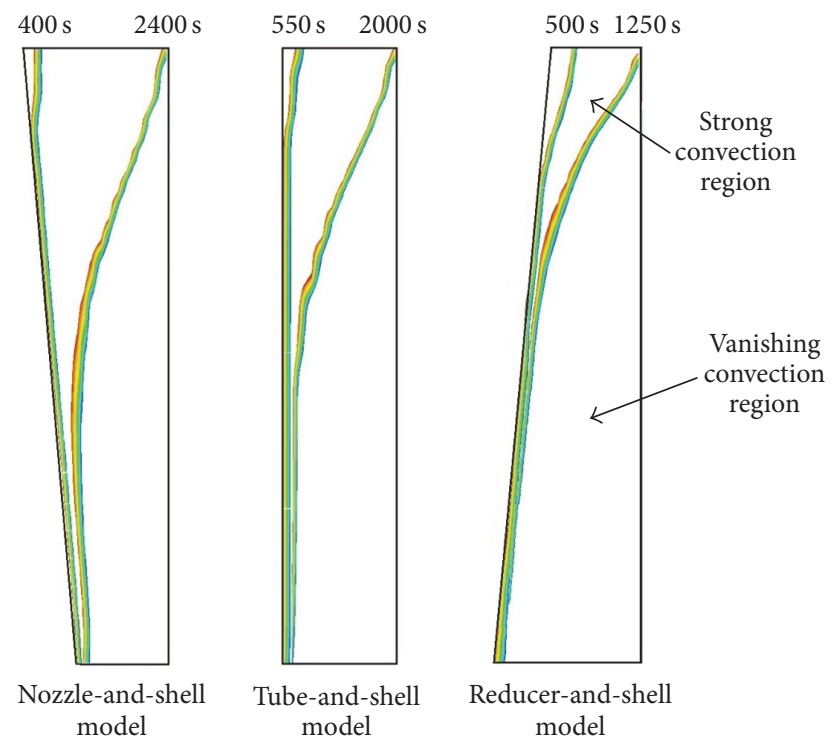

FIGURE 11: Liquid-solid interface at the time there was a change of Nusselt numbers.

Strong convection that occurs with the nozzle-and-shell model is the longest, followed by tube-and-shell and reducerand-shell models, respectively.

\section{Conflicts of Interest}

The authors declare that they have no conflicts of interest.

\section{Acknowledgments}

The authors thank DRPM Ristekdikti for the financial support through Research Grant no. 006/SP2H/LT/DRPM/II/ 2016.

\section{References}

[1] A. S. Fleischer, Thermal Energy Storage Using Phase Change Materials: Fundamentals and Applications, SpringerBriefs in Thermal Engineering and Applied Science, Springer, 2015.

[2] Technology Brief, “Thermal energy storage," IEA-ETSAP and IRENA, Technology Brief E17, 2013, http://www.etsap.org, http:// www.irena.org.

[3] A. Trp, "An experimental and numerical investigation of heat transfer during technical grade paraffin melting and solidification in a shell-and-tube latent thermal energy storage unit," Solar Energy, vol. 79, no. 6, pp. 648-660, 2005.

[4] R. Hendra, Hamdani, T. M. I. Mahlia, and H. H. Masjuki, "Thermal and melting heat transfer characteristics in a latent heat storage system using mikro," Applied Thermal Engineering, vol. 25, no. 10, pp. 1503-1515, 2005.

[5] N. S. Dhaidan, J. M. Khodadadi, T. A. Al-Hattab, and S. M. Al-Mashat, "Experimental and numerical investigation of melting of phase change material/nanoparticle suspensions in a square container subjected to a constant heat flux," International Journal of Heat and Mass Transfer, vol. 66, pp. 672-683, 2013.
[6] C. J. Ho and J. Y. Gao, "An experimental study on melting heat transfer of paraffin dispersed with $\mathrm{Al}_{2} \mathrm{O}_{3}$ nanoparticles in a vertical enclosure," International Journal of Heat and Mass Transfer, vol. 62, no. 1, pp. 2-8, 2013.

[7] H. Shokouhmand and B. Kamkari, "Experimental investigation on melting heat transfer characteristics of lauric acid in a rectangular thermal storage unit," Experimental Thermal and Fluid Science, vol. 50, pp. 201-222, 2013.

[8] M. J. Hosseini, A. A. Ranjbar, K. Sedighi, and M. Rahimi, "A combined experimental and computational study on the melting behavior of a medium temperature phase change storage material inside shell and tube heat exchanger," International Communications in Heat and Mass Transfer, vol. 39, no. 9, pp. 1416-1424, 2012

[9] A. V. Arasu and A. S. Mujumdar, "Numerical study on melting of paraffin wax with $\mathrm{Al}_{2} \mathrm{O}_{3}$ in a square enclosure," International Communications in Heat and Mass Transfer, vol. 39, no. 1, pp. 8-16, 2012.

[10] T. Kousksou, M. Mahdaoui, A. Ahmed, and A. A. Msaad, "Melting over a wavy surface in a rectangular cavity heated from below," Energy, vol. 64, pp. 212-219, 2014.

[11] A. Sharma, V. V. Tyagi, C. R. Chen, and D. Buddhi, "Review on thermal energy storage with phase change materials and applications," Renewable and Sustainable Energy Reviews, vol. 13, no. 2, pp. 318-345, 2009.

[12] N. Ukrainczyk, S. Kurajica, and J. Šipušić, "Thermophysical comparison of five commercial paraffin waxes as latent heat storage materials," Chemical and Biochemical Engineering Quarterly, vol. 24, no. 2, pp. 129-137, 2010.

[13] J. Gasia, L. Miró, A. de Gracia, C. Barreneche, and L. F. Cabeza, "Experimental evaluation of a paraffin as phase change material for thermal energy storage in laboratory equipment and in a shell-and-tube heat exchanger," Applied Sciences, vol. 6, no. 5, article 112, 2016.

[14] Chapter 21. Modeling Solidification and Melting, Fluent, New York, NY, USA, 2001 


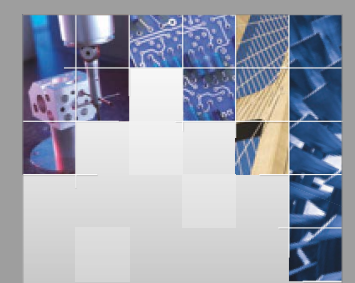

\section{Enfincering}
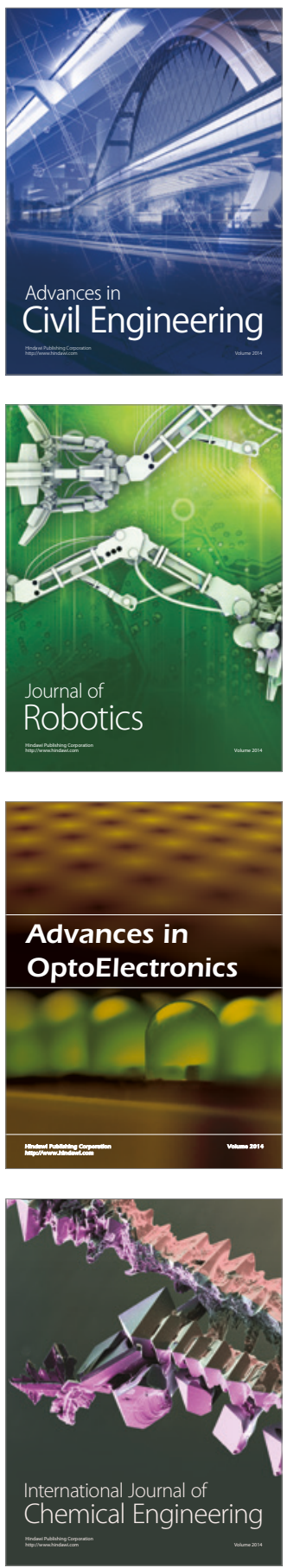

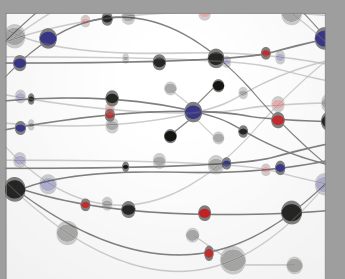

The Scientific World Journal

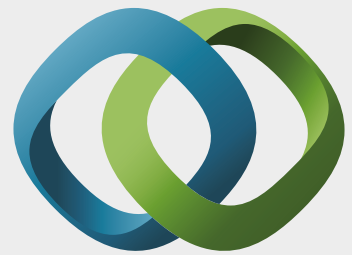

\section{Hindawi}

Submit your manuscripts at

https://www.hindawi.com
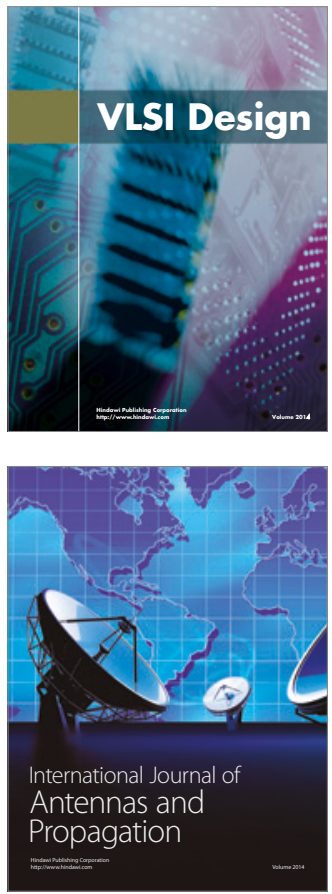

\section{Rotating}

Machinery
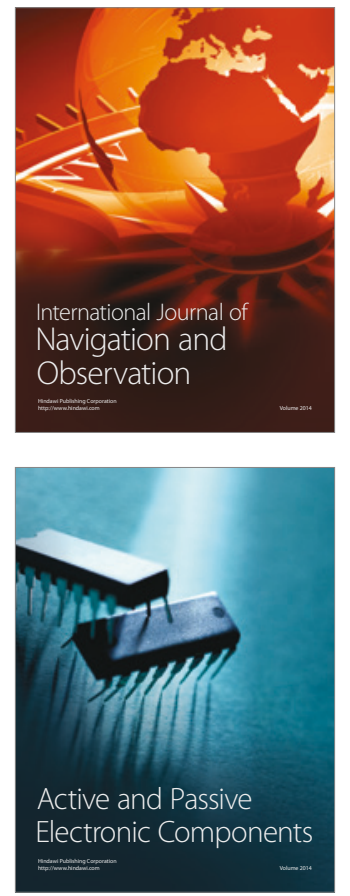
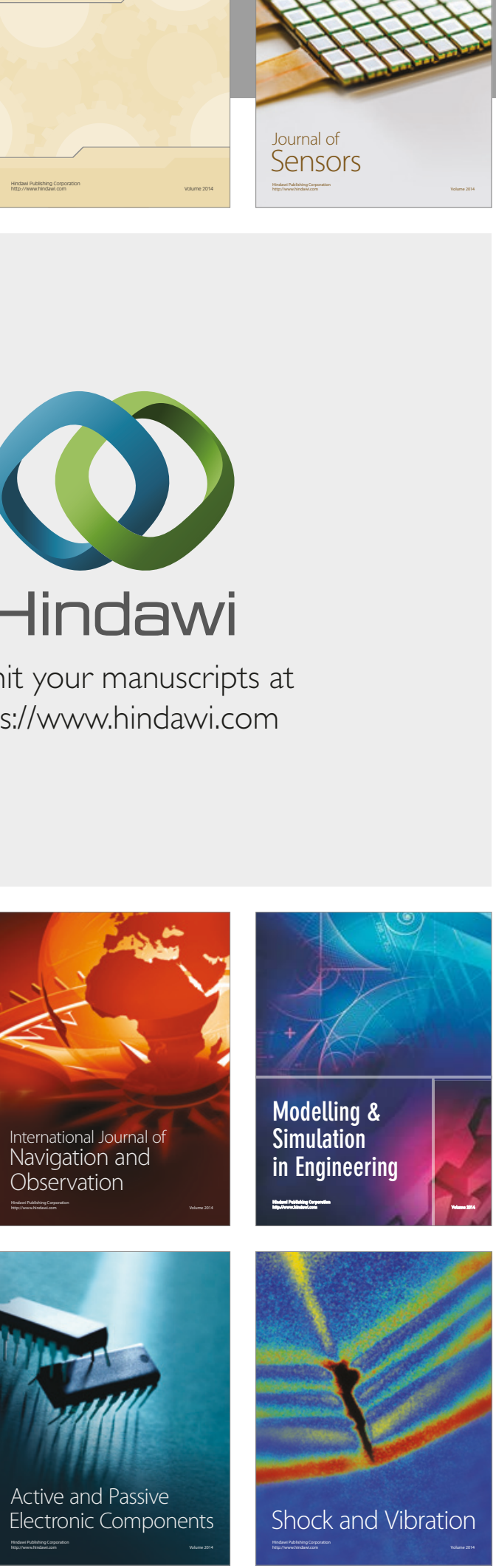
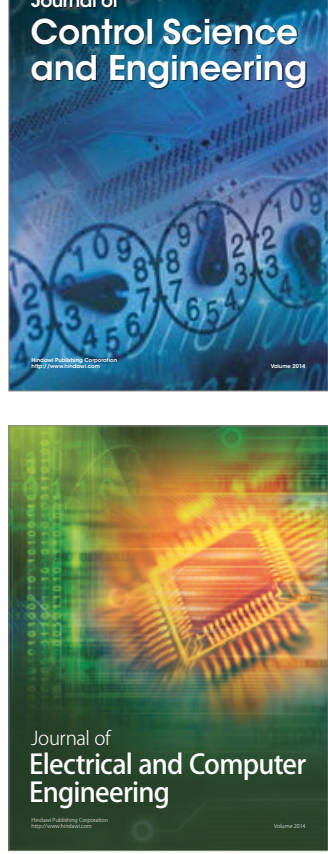

Distributed

Journal of

Control Science

and Engineering
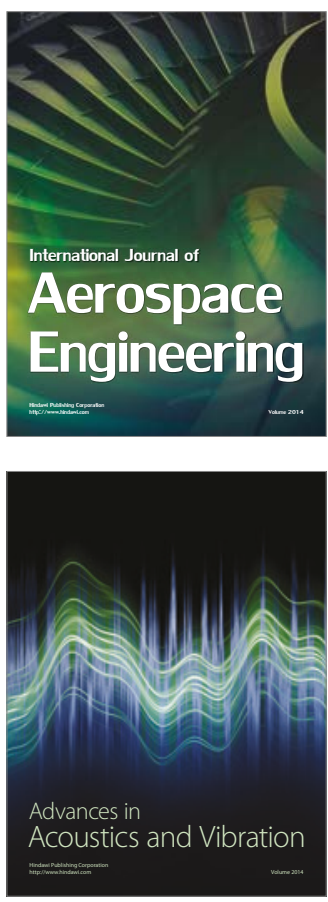

Sensor Networks 